\title{
Cardiac imaging techniques in the diagnosis of angiosarcoma of the heart: report of two cases.
}

\author{
Antoon E. Weyne, Guy R. Heyndrickx, Claude C. Cuvelier, Marcel B. Afschrift, \\ Marc F. Kunnen and Fritz E. Derom \\ Departments of Cardiology, Pathology, Internal Medicine, Radiology and Cardiopulmonary Surgery, State \\ University of Gent, Belgium.
}

\begin{abstract}
Summary: Angiosarcoma of the heart is a rare and highly malignant tumour. Most of the reported cases have been diagnosed post mortem. In a one year period two cases were diagnosed during life and surgically treated. The only possible hope for survival is early diagnosis and surgical removal. Our cases illustrate the contribution of cardiac imaging techniques to early diagnosis and the feasibility of radical excision of this tumour.
\end{abstract}

\section{Introduction}

Primary cardiac tumours have an extremely low incidence, and clinical signs and symptoms are variable. Sometimes no symptoms at all are present, while in other cases the clinical picture is confused by a large variety of cardiovascular and systemic symptoms. Hence the antemortem diagnosis of a cardiac tumour is among the most challenging in medicine (Colucci \& Braunwald, 1980).

Generally about $75 \%$ of all cardiac tumours are considered to be histologically benign. Almost all malignant cardiac tumours are sarcomas of which angiosarcoma and rhabdomyosarcoma are most commonly encountered (Colucci \& Braunwald, 1980). So far approximately 70 cases of angiosarcoma have been reported (Bennett et al., 1982) but most of them were only diagnosed at autopsy.

The present paper reports two patients in whom the diagnosis of angiosarcoma was made during life. In both cases the diagnosis of a heart tumour was made very early by non-invasive methods (two-dimensional echocardiography and computed tomography) in spite of very mild symptoms. Coronary angiography visualized the vascular pattern of the tumour.

In both patients confirmation of malignity was obtained by cytologic examination of aspirated pericardial fluid. Definite diagnosis was made by

Correspondence: Antoon Weyne, M.D., Department of Cardiology, University Hospital, De Pintelaan 185, B-9000 Gent, Belgium.

A.ccepted: 8 May 1984 histological examination after surgical removal of the tumour.

\section{Case reports}

\section{Patient 1}

A 52 year old woman was admitted to the hospital with suspicion of a cardiac tumour; at that time she was in NYHA functional class IV. Six months before admission a superior cavography was performed because of swelling of the eyelids; a lacunar filling defect was observed at the transition of the superior vena cava into the right atrium. Enhanced computed tomography (CT) confirmed the presence of a filling defect of the right atrium (Figure 1A). Further investigations were refused at that time. On admission Mmode echocardiography confirmed a large pericardial effusion. Two-dimensional echocardiography also revealed a right atrial tumour. Blood-stained pericardial fluid was aspirated which contained malignant cells. Angiography revealed a mass in the right atrium and a selective coronary angiography showed a patch of neovascularization arising both from the left and the right coronary artery (Figure 1B).

A sternotomy was performed. The pericardium contained five hundred $\mathrm{ml}$ of haemorrhagic fluid. The right atrium was filled by a fist-sized tumour which expanded into the auricle. Approximately ninety percent of the tumour could be removed and the right atrium was reconstructed by means of a pericardial patch. After a six weeks treatment with chemotherapy

(C) The Fellowship of Postgraduate Medicine, 1985 
A

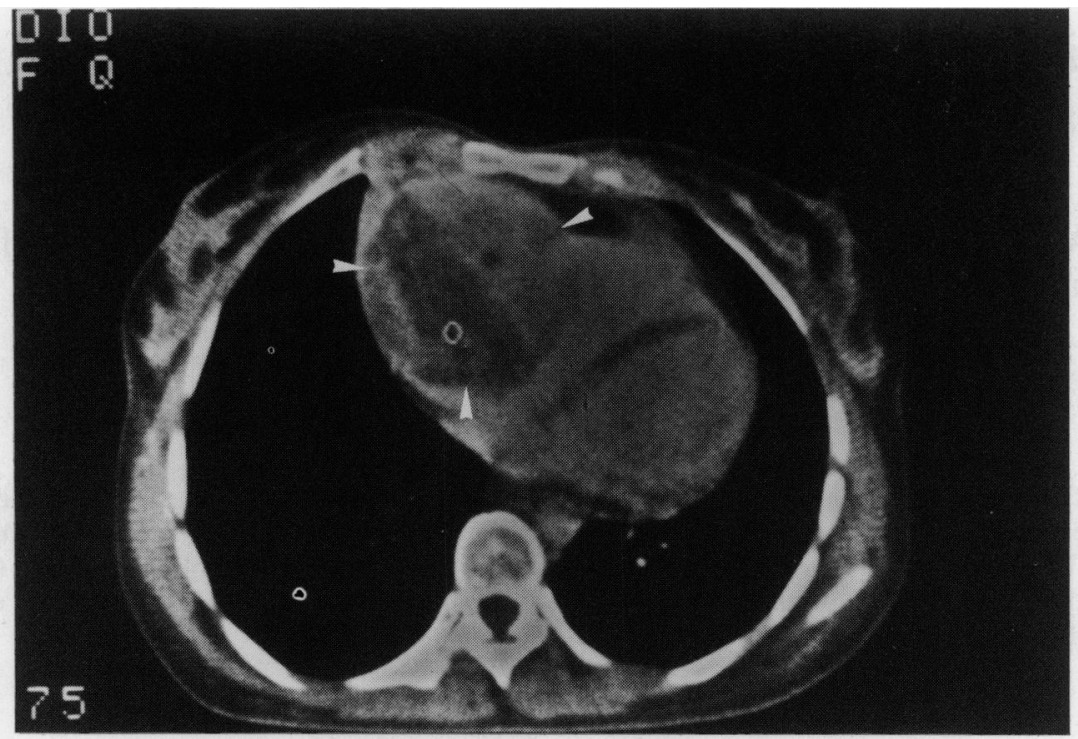

B

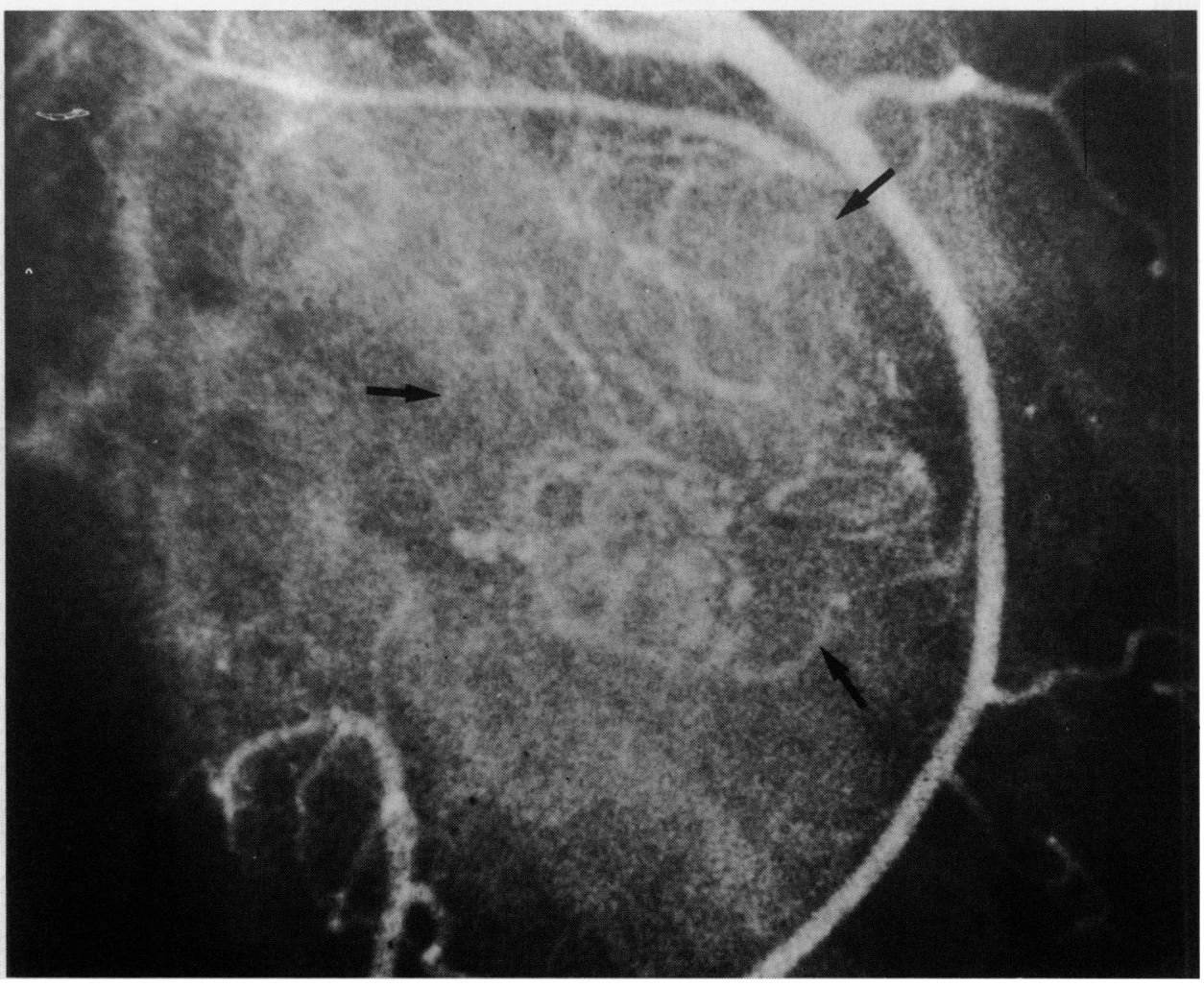

Figure 1 Angiosarcoma. (A) Computed tomography. $7 \mathrm{~mm}$ thick scan at the level of right atrium, during rapid infusion of contrast material. The tumour (arrowheads) is revealed as a lacunar filling defect, presenting a solid tissue density (55 H.U.). (B) Right coronary angiography in the right anterior oblique view: patch of neovascularization (arrows) into the tumoral area, corresponding to the right atrium. 
ventricular fibrillation occurred. All attempts to reanimate failed. An autopsy did not reveal metastases.

\section{Patient 2}

A 30 year old nurse presented in February 1983 with a two months history of palpitations and vertigo. Initially, physical examination, electrocardiogram and chest $\mathrm{X}$-ray were normal. A Holter registration demonstrated a brief episode of intermittent atrial fibrillation. On digitalis and propranolol she became symptom free. She was referred for further investigation because of an abnormal enlargement of the right heart border on radioscopy. M-mode echocardiography at that moment was interpreted as normal. On admission two-dimensional echocardiography revealed an enlarged right atrium containing a nine $\mathrm{cm}$ large tumour (Figure 2), and pericardial effusion. Pericardial puncture under sonographic guidance yielded haemorrhagic fluid, which contained malignant cells. Coronary arteriography showed neovascularization origin- ating from an atrial branch of the right coronary artery.

The tumour together with the lateral wall of the right atrium and part of the tricuspid valve annulus were excised, and a VVI pacemaker was inserted. The operation was not curative: the section margin at the tricuspid valve was invaded by tumour. Twenty months after surgery the patient is still alive in NYHA functional class II. Chemotherapy was avoided with the aim to provide her an optimal quality of life. The tricuspid regurgitation is responding to a medical treatment of salt intake restriction and digitalis.

In both cases microscopic examination revealed a similar vascular tumour with large necrotic portions and variable pattern. In some areas there were predominantly anastomosing blood vessels covered with an atypical endothelium. In other parts the tumours were solid and the cells were closely packed and spindle-shaped. There was nuclear pleomorphism and a high mitotic activity. Angiosarcoma was diagnosed.

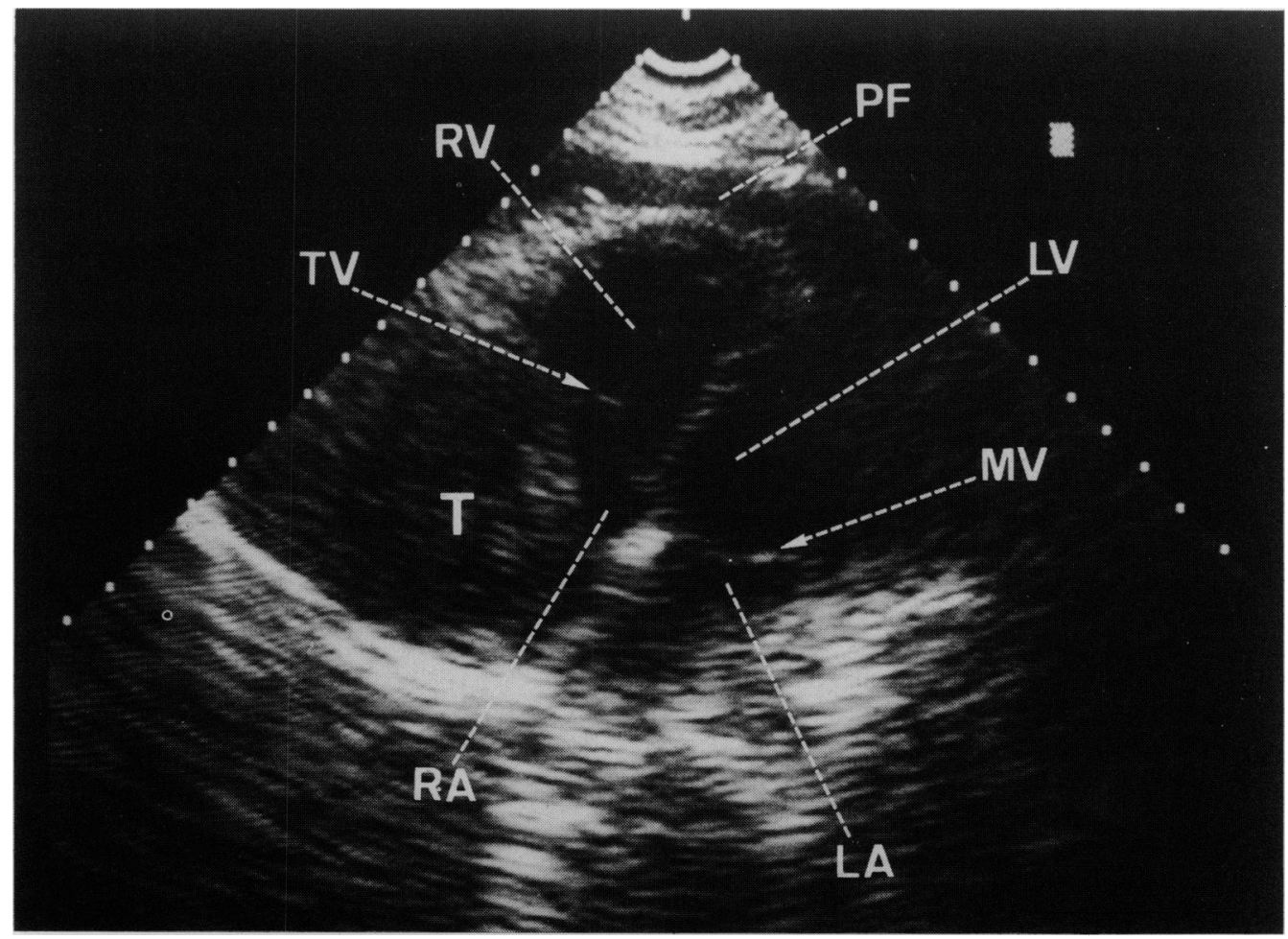

Figure 2 Angiosarcoma. Apical four chamber view shows an enlarged right atrium (RA) filled by a tumour (T). $L A=$ left atrium, $L V=$ left ventricle; $M V=$ mitral valve; $P F=$ pericardial fluid; $R V=$ right ventricle; TV $=$ tricuspid valve. 


\section{Discussion}

Angiosarcoma of the heart is uncommon and has been reported under a variety of names such as cavernous spindle-cell sarcoma, primary Kaposi's sarcoma, malignant endothelioma, haemangioreticuloendothelioma and haemangioendothelioblastoma. The high malignancy of this tumour is illustrated by a median survival of three months (Strohl, 1976). Despite the rare incidence there is a remarkable uniformity in the clinical picture caused by the almost unvariable right atrial location of the tumour with eventual infiltration into the pericardium. The clinical manifestations result in obstruction of the superior or inferior vena cava, arrhythmia, thoracic pain, right heart decompensation, haemorrhagic pericardial effusion and cardiac tamponade and/or metastasis (Bennett et al., 1982) into the lung, pleura, liver and lymph nodes, and rarely into brain, kidney or adrenal glands.

Our cases illustrate the diagnostic importance of cardiac imaging techniques such as echocardiography, computed tomography, angiography and coronary angiography for detecting cardiac tumours. Because the tumour is usually localized in the right atrium, $\mathrm{M}$ - mode echocardiography is less sensitive than twodimensional echocardiography in detecting angiosar- $\frac{\varrho}{2}$ comas of the heart. In the second patient the diagnosis $\mathbb{\infty}$ was even missed by M-mode echocardiography. When ${ }_{C}$ a right-sided cardiac tumour is suspected, a two dimensional echocardiogram should be carried outs? (Stern et al., 1981). This technique is more sensitiveo and specific than contrast angiography and tech-o netium-labelled erythrocyte cardiac imaging (Bennett $\frac{\bar{\rho}}{\bar{s}}$ et al., 1982) in detecting right atrial masses. Echocar- $₫$ diography offers a direct image of the tumour, whereas in other techniques the tumoral mass is only indirectly visualized as a filling defect. CT-scan examination for. the diagnosis of cardiac tumours seens less sensitive $\vec{\omega}$ than echocardiography, since the resolution of the image can be impaired by motion artefacts (Scully $e t . \overrightarrow{0}$ al., 1983). Yet it was a major diagnostic tool in our first 3 . patient. Recent reports indicate that a wide variety of 9 cardiac tumours can be detected by CT-scan (Gross $e t-\vec{v}$ al., 1983). The vascular supply and degree of vas- $\vec{\omega}$ cularity of heart tumours is visualized by selective $\tilde{N}^{-}$ coronary angiography. However, the so-called neovascularity shown by coronary angiography is not? specific for a heart tumour. The same neovascularity -

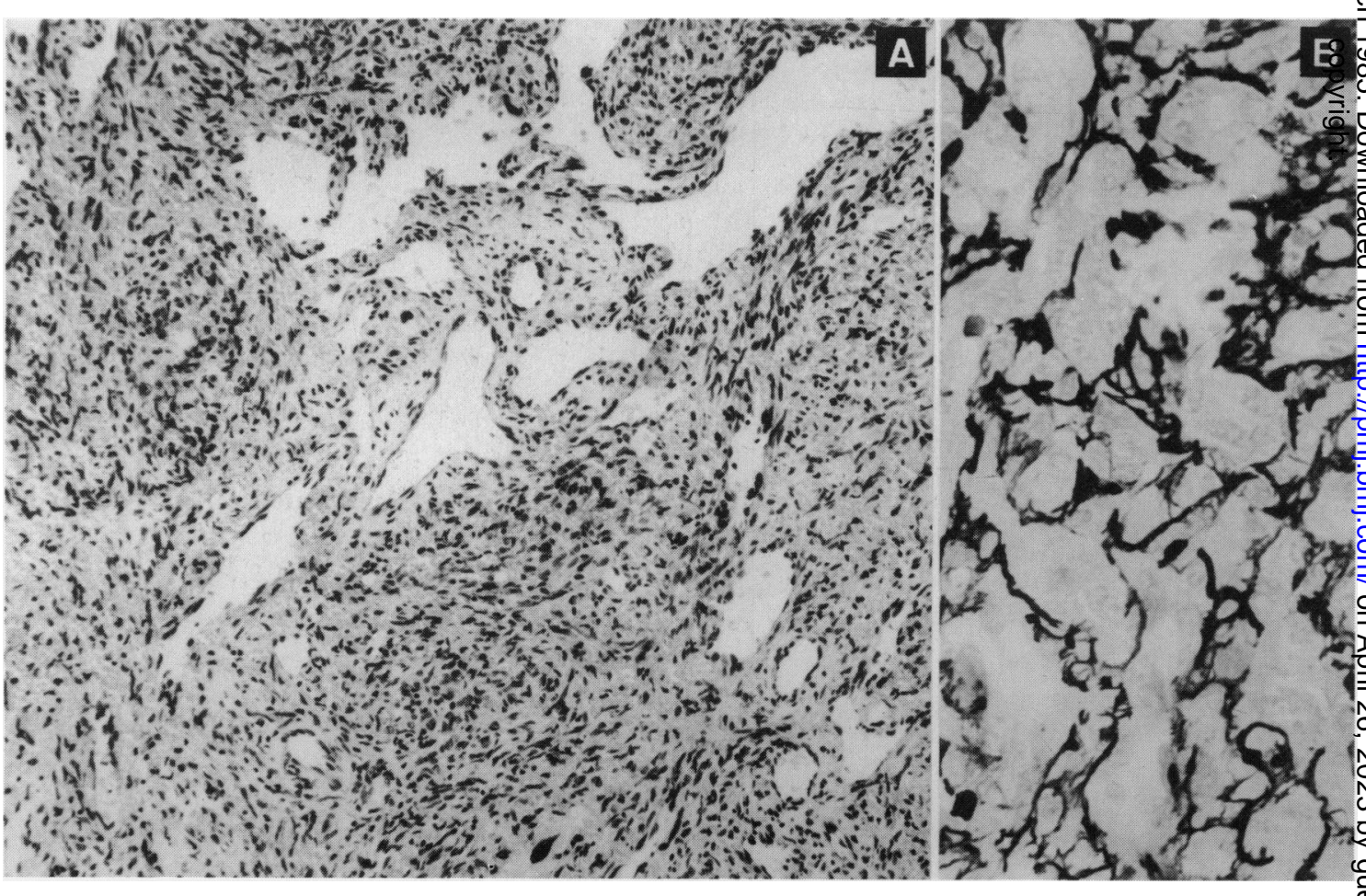

Figure 3 (A) Angiosarcoma (case 2) consisting of anastomosing vascular channels between which solid areas of tumorous spindle cells occur (H.E. $\times 160)$. (B) The reticulin stain clearly demonstrates the vascular pattern of the tumour $(\times 640)$. 
can be and has been observed in hearts with a mural thrombus (Ugarte et al., 1982). Digital video subtraction angiography has also been reported as a noninvasive investigation for detecting cardiac tumours (Lackner et al., 1982).

The diagnosis of angiosarcoma of the heart is seldom made ante mortem. Shackell et al. (1979) found only fifteen cases in the literature in which the diagnosis was confirmed before death. Clinical diagnosis of a right atrial mass was made in our two patients by cardiac imaging techniques. In both cases the diagnosis of a malignant heart tumour was made by cytological examination of the aspirated pericardial fluid. Endomyocardial biopsy, using the jugular venous approach, could be an elegant procedure for the tissue diagnosis of a primary cardiac tumour (Ursell \& Fenoglio, 1983). Nevertheless as these tumours are highly vascularized this technique may be dangerous because of the likelihood of uncontrolled bleeding (Scully et al., 1983). An open exploration of the heart

\section{References}

BENNETT, M.T., WEBER, P.M. \& KILLEBREW E.K. (1982). Primary angiosarcoma of the heart detected by technetium-labelled erythrocyte cardiac imaging. Cancer, 49, 2587.

COLUCCI, W.S. \& BRAUNWALD, E. (1980). Primary tumours of the heart. In BRAUNWALD, E. Heart disease, a textbook of cardiovascular medicine, p. 1501. W.B. Saunders Company: Philadelphia, London, Toronto.

GROLLIER, G., COMMEAU, P., ISELIN, M., BOREL, B., ROUSSELOT, P., MAIZA, D., KHAYAT, A., FOUCAULT, J.P. \& POTIER J.C. (1983). Angiosarcome localisé au niveau des cavités cardiaques droites. A propos d'un cas. Annales de Cardiologie et d'Angéiologie, 32, 59.

GROSS, B.H., GLAZER, G.M. \& FRANCIS, I.R. (1983). CT of intracardiac and intrapericardial masses. American Journal of Roentgenology, 140, 903.

LACKNER, K., HARDER, Th., FRANKEN, Th., MATTERN, H. \& FRICKE, G.R. (1982). Nachweis intrakardialer Tumoren mit der digitalen Videosubstrakionsangiographie. Fortschritte auf dem Gebiete der Röntgenstrahlen und der Nuklearmedizin, 137, 632. confirmed the diagnosis of angiosarcoma.

Angiosarcoma of the heart is known to be highly malignant and the only possible hope for survival is early diagnosis and surgical removal. In most reported cases resection was not possible (Ugarte et al., 1982; Bennet et al., 1982; Grollier et al., 1983). Irradiation therapy and/or chemotherapy confirmed the impression that this therapy had at least a palliative effect on this tumour. Only a few cases of treatment by resection of the tumour have been reported.(Sørlie et al., 1984).

In the last decade diagnosis of angiosarcoma of the heart has become more easy by a number of diagnostic techniques that are at our disposal. Two-dimensional echocardiography is most convenient for that purpose; it is non-invasive and clearly outlines the right atrium in most patients. Confirmation of a mass may be obtained by CT-scanning, while vascularization of the tumour is evaluated by coronary angiography. Diagnosis is ultimately obtained by histological examination of the tumour.
SCULLY, R.E., MARK, E.J., \& MCNEELY, B.U. (1983). Case 4 1983. Presentation of case. New England Jowrnal of Medicine, 308, 206.

SHAKELL M., MITKO, A., WILLIAMS, P.L. \& SUTTON G.C. (1979). Angiosarcoma of the heart. British Heart Journal, $41,498$.

SØRLIE, D., MYHRE, E.S.P. \& STALSBERG, H. (1984). Angiosarcoma of the heart. Unusual presentation and survival after treatment. British Heart Journal, 51, 94.

STERN, M.J, COHEN, M.V., FISH, B. \& ROSENTHAL, R. (1981). Clinical presentation and non-invasive diagnosis of right heart masses. British Heart Journal, 46, 552.

STROHL, P.K. (1976). Angiosarcoma of the heart: a case study. Archives of Internal Medicine, 136, 928.

UGARTE, M., ALONSO-PULPON, L., GONZALEZ-VILLA, J., DE ARTAZA, M. \& MARTIN-JUDEZ, V. (1982). Coronary arteriographic findings in a case of primary angiosarcoma of the heart. European Heart Journal, 3, 577.

URSELL, P.C. \& FENOGLIO, J.J. (1983). Endomyocardial biopsy. Established diagnostic procedure. Chest, 84, 122. 